\title{
The effect of monetary incentive in paired associate learning using a differential method'
}

\author{
Willard F. Harley, Jr. \\ UNIVERSITY OF CALIFORNIA, SANTA BARBARA
}

\begin{abstract}
Abstraet
Two groups of human Ss were tested in a paired associate learning task using the method of anticipation with 13 pairs of CVC trigrams of low association value. Both groups were told that the learning of trigrams of a certain background color (yellow, white) would result in a reward of 25 cents for each correct response on a predetermined trial. The interval between the stimulus trigram onset and response trigram onset for each pair was $4 \mathrm{sec}$. for both groups. But the interval between the response trigram onset of one pair and the stimulus trigram onset of the next pair (R-S interval) was $4 \mathrm{sec}$. for one group and $1.3 \mathrm{sec}$. for the other group. The $4 \mathrm{sec}$. R-S interval group learned the high incentive trigrams (HIT) significantly faster than the low incentive trigrams (LIT), but the difference was not significant in the $1.3 \mathrm{sec}$. group. Also, the length of the $\mathrm{R}-\mathrm{S}$ interval had a significant effect on the ease of recall of HIT relative to LIT. The amount recalled depended upon the total amount of time permitted for looking at the pairs rather than upon the total number of trials or overt recitations.
\end{abstract}

\section{Introduction}

The purpose of this experiment is to investigate the effect of a monetary incentive upon the learning of paired associate trigrams. It has been possible to demonstrate an effect of incentive magnitude upon learning in animal studies using differential methods, but results are ambiguous when absolute methods are utilized (Pubols, 1960). As a result, a differential method was used in this study on the assumption that this method would be more sensitive to the effect of monetary incentive magnitude than an "absolute" procedure.

This study is an attempt to answer two questions: (1) Can a human S learn paired associate trigrams with high incentive in less time than those with low incentive, and (2) if so, what conditions effect such behavior?

It is assumed that other incentives in addition to the monetary incentive are present in this learning situation. Therefore, those trigrams which are rewarded monetarily when learned will be referred to as high incentive trigrams (HIT) and those which are not rewarded monetarily when learned are low incentive trigrams (LIT) rather than no incentive.

\section{Subjects}

Forty students enrolled in an introductory psychology course at the University of California, Santa Barbara, served as Ss. They volunteered for the experiment and did not know that they would be paid.

\section{Apparatus}

A small Gerbrands Memory Drum connected to a Hunter recycling timer was used to present the stimuli. The timer and memory drum were set such that the interval between the stimulus trigram and the response trigram (S-R interval), and the interval between the response trigram and the next stimulus trigram (R-S interval) could be varied independently. The intervals were measured from the onset of one trigram to the onset of the next trigram. The stimuli consisted of 26 CVC trigrams of low association value $(M<8)$. These were randomly divided into 13 pairs. Two background colors, yellow and white, were chosen to provide a means for differentiating the pairs. The pairs were randomly placed in a list and the color backgrounds were assigned in an alternating manner (i.e., the first pair was on a yellow background, second pair on a white background, third yellow, etc.).

\section{Procedure}

The $\mathrm{S}$ was instructed to try to anticipate the second word of each pair of trigrams presented. He was to recite aloud the stimulus trigram immediately when it appeared, and recite the response trigram before it appeared, or if incorrect, when it appeared. The $\mathrm{E}$ recited the pairs with $S$ during the first trial to help in the pronunciation of the trigrams. He was not told how many trials there would be. The $\mathrm{S}$ was told that seven of the pairs would have a yellow background and six pairs would have a white background and that he was to learn as many of the pairs as he could. Then $\mathrm{S}$ was instructed that on one predetermined trial, the number of response trigrams correctly recited of a particular background color (yellow, white) would be counted and he would be given 25 cents for each one. The color was yellow for groups $1 \mathrm{~A}$ and $1 \mathrm{~B}$ and white for groups $2 \mathrm{~A}$ and $2 \mathrm{~B}$ (10 $\mathrm{Ss}$ in each group). After the experiment, Ss were paid.

There was a $4 \mathrm{sec}$. S-R interval for all groups. Since it took about $2 / 3 \mathrm{sec}$. to recite the stimulus word, $\mathrm{S}$ had about $3-1 / 3$ sec. to recall the response word. The $\mathrm{R}-\mathrm{S}$ interval was varied between groups. In groups $1 \mathrm{~A}$ and $2 \mathrm{~A}$ the interval was $4 \mathrm{sec}$. In groups $1 \mathrm{~B}$ and $2 \mathrm{~B}$ it was $1.3 \mathrm{sec}$. The total amount of learning time was the same in each group (780 sec.). Group A had 14 trials and group B had 21 trials. The presentation rate for group A was 8 sec. per pair and for group B, $5.3 \mathrm{sec}$. Results

The line connecting squares in Figs. 1 and 2 represents LIT and the line connecting circles represents HIT. 


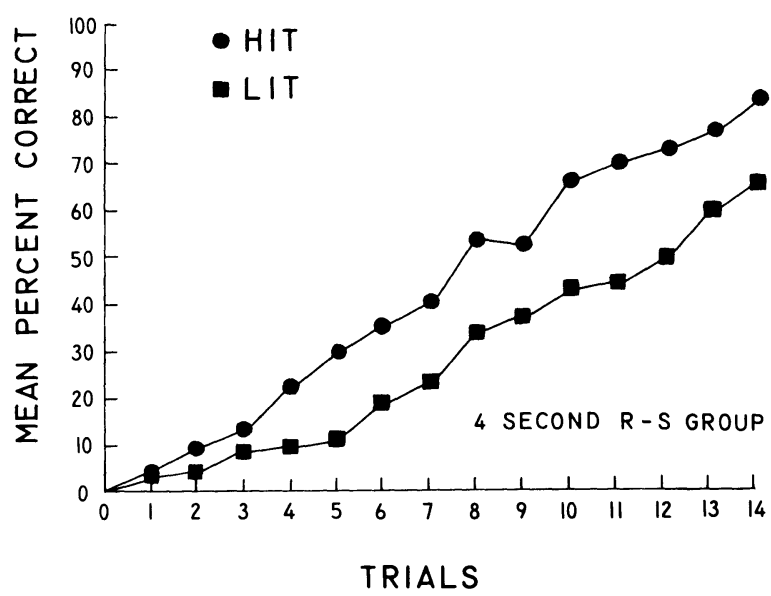

Fig. 1. Mean percent correct recall for $4 \mathrm{sec}$. R-S interval group with regard to high incentive trigrams (HIT) and low incentive trigrams (LIT).

The mean percent correct for group A (4 sec. R-S interval) is shown in Fig. 1 as a function of trials and the mean percent correct for group B ( 1.3 sec. $\mathrm{R}-\mathrm{S}$ interval) is shown in Fig. 2. The last pair in the list for all groups was not considered in the analysis since the interval between the last response and the first stimulus of the list was longer than the other R-S intervals. This added interval was to irdicate to the $\mathrm{S}$ that the list had ended.

Both R-S interval groups recalled more high incentive than low incentive trigrams but the difference was statistically significant only for the 4 sec. R-S interval group. A t-test between correlated means found the difference in the $4 \mathrm{sec}$. group significant at the .001 level $(t=4.71)$ whereas in the $1.3 \mathrm{sec}$. group the difference was not significant at the .05 level $(t=1.54)$.

In the $4 \mathrm{sec}$. R-S interval group 18 out of 20 recalled more high incentive trigrams, whereas in the $1.3 \mathrm{sec}$. group only 11 out of 20 learned more high incentive trigrams.

The difference scores between the number of correct HIT and correct LIT were calculated for each $S$ on trials in which total presentation time had been the same in both $\mathrm{R}-\mathrm{S}$ interval groups. Trials $2,4,6,8$, 10,12 , and 14 in groups $1 \mathrm{~A}$ and $2 \mathrm{~A}$ were given at the same time as trials $3,6,9,12,15,18$, and 21 in groups $1 \mathrm{~B}$ and $2 \mathrm{~B}$ respectively. A $2 \times 5$ analysis of variance for repeated measures performed on the differences of the 4 sec. R-S interval group and the differences of the 1.3 sec. $\mathrm{R}-\mathrm{S}$ interval group indicated a difference

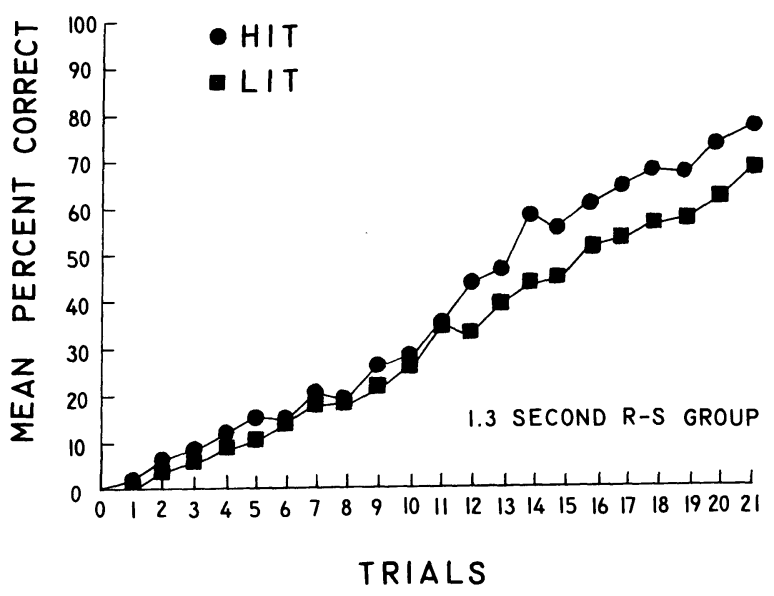

Fig. 2. Mean percent correct recall for 1.3 sec. R-S interval group with regard to high incentive trigrams (HIT) and low incentive trigrams (LIT).

between the groups which was significant at the .05 level. The main effect of trials and trials by groups interaction failed to reach significance.

\section{Diseussion}

The effect of monetary incentive upon human paired associate learning as a function of the rate of presentation has been neglected in the literature. This study points to two important features of human learning that have not been adequately considered by contemporary learning theories: First, as has been pointed out by Bugelski (1963), among others, total presentation time rather than trials determine the amount of learning, and second, the R-S interval has an important effect upon whether Ss will learn HITs faster than LITs. This last point cannot convincingly be explained by changes in discrimination of the background color as a function of $\mathrm{R}-\mathrm{S}$ interval since the 4 sec. S-R interval for all groups was enough time to adequately discriminate background color.

Before any attempt is made to explain this data, it is felt that the effect of these variables should be more fully investigated.

\section{References}

BUGELSKI, B. R. Presentation time, total time, and mediation in paired-associate learning. J. exp. Psychol., 1962, 63, 409-412. PUBOLS, BENJAMIN H., JR. Incentive magnitude, learning, and performance in animals. Psychol. Bull., 1960, 57, 89-115.

Note

1. The author is indebted to David M. Messick for his guidance throughout the course of this study. 